\title{
Donuk/donmuş omuz
}

\author{
Frozen shoulder \\ Yakup Barbaros Baykal', Tolga Atay ${ }^{1}$, Onur Kocadal ${ }^{2}$ \\ 1Süleyman Demirel Üniversitesi Tıp Fakültesi, Ortopedi ve Travmatoloji Anabilim Dalı, Isparta \\ ${ }^{2}$ Ankara Eğitim ve Araştırma Hastanesi, Ortopedi ve Travmatoloji Kliniği, Ankara
}

Donuk omuz, yaşam konforunu ciddi şekilde bozan, ağrı ve ilerleyici hareket kısıtlılığı ile karakterize bir hastalıktır. Son yıllarda fizyopatolojinin ve biyokimyasal temellerinin daha iyi anlaşı Iması, sınıflama ve tedavi yaklaşımlarına bir takım yenilikler getirmiştir. Donuk omuzun temel tedavisi; egzersiz ağırıklı fizik tedavidir ve eklemi hareketsiz bırakmamak esastır. Hastalığın ilk aşamalarında farmakolojik tedaviden de fayda görülür. Erken dönemde tedavi almayan ve ileri derecede omuz hareket kısıtlılığı gelişen kişilerde cerrahi tedavi ön plandadır. Günümüzde artroskopik prosedürlerin gelişmesi ve yaygınlaşmasıyla beraber açık cerrahi yaklaşımların yerini artroskopik girişimler almaktadır.

Anahtar sözcülkler: omuz ağrısı; yapışıcı kapsülit; eklem kapsülü; doku yapışıklıkları
Frozen shoulder, a disease that seriously disturbs patients quality of life, is characterized with pain and progressive restriction of motion. Increased awareness of its pathophysiology and biochemical features have resulted in the development of new classification systems and altered the treatment methods. The main treatment option of frozen shoulder is physiotherapy which is mostly composed of physical exercises and continuous movement of the joint. The pharmacological treatment has also benefits in the early stages of the disease. Nowadays, with the widespread application of arthroscopic procedures, arthroscopic treatment takes the place of open surgery.

Key words: shoulder pain; adhesive capsulitis; joint capsule; tissue adhesions

kullanmıştır. ${ }^{[3]}$ Lundberg, donuk omuzu primer veya idiopatik ve sekonder olmak üzere sınıflandırmıştır. Harryman ve Neviaser, muhtemel nedenler olarak endokrin, immünolojik, inflamatuvar ve biyokimyasal değişiklikleri ileri sürmüşler, Janda ise, diabetli hastalarda artmış insidansı göstermiştir. ${ }^{[4]}$

\section{EPIDEMIYOLOJi}

Prevalansı tam olarak bilinmemektedir. Genel popülasyonun \%2-5'ini etkilediği bildirilmiştir. Ancak diyabetik hastalarda yaygınlığı \%11 olarak bildirilmiştir. Tip I diyabetli hastaların yaşamları boyunca donuk omuz geçirme şansı yaklaşık \%40'tır. Hipertiroidili ve hipertrigliseridemili hastalarda da sık görülür. Irk farklılığı gösterilememiştir.[4,5]

\section{PATOLOJi}

Fizyopatolojik durumun, eklem kapsülünün sinovyal enflamasyonu ve sonrasında gelişen fibrozis olduğuna

- Illetişim adresi: Onur Kocadal, Ankara Eğitim ve Araştırma Hastanesi, Ortopedi ve Travmatoloji Kliniği, Ankara

Tel: 0532 - 3364878 e-posta: onurkocadal@gmail.com

- Geliş tarihi: 20 Ağustos 2013 Kabul tarihi: 25 Ekim 2013 
inanılmaktadır. Glenohumeral eklem kapsülünün yanı sıra, korakohumeral ligament, rotator interval ve subakromial bursa yapıları da etkilenir. Artan fibrozis, omuz eklemi hacmini azaltır ve bu da hareket kısıtlıığı ile sonuçlanır.

Eklem kapsülünde IL-1 $\alpha$, IL-1 $\beta$, TNF- $\alpha$, COX-1 ve COX-2 gibi aracılarda artış saptanmıştır. ${ }^{[6]}$ Bu durum inflamatuvar ve otoimmün mekanizmaların rolünü açıklayabilir. Hiperselülarite ve fibroblastik proliferasyona ek olarak, PGP9.5 ve GAP43 nöronal protein overekspresyonu saptanmış, bu durum eklem kapsülünde neoangionezise bağlı kapsüler hipertrofi ve yaygın ağrı ile ilişkilendirilmiştir. ${ }^{[7]}$

Kontrakte anterior yapıların gevşetilmesi sırasında elde edilen örneklerden yapılan biyopsilerde farklı bulgular elde edilmiştir. Bunlar: kapsül ve korakohumeral ligamentte kalınlaşma; kompakt, hücresel ve yoğun fibröz doku; çoğunlukla fibroblast varlığı, bazen artmış damarlanma ve hemen hemen bozulmamış sinovyal örtü; fibrozis, hyalinizasyon, fibrinoid dejenerasyon ve vasküler villöz sinovitis; olgunlaşmış nedbe dokusu, fakat herhangi bir aktif inflamatuvar hücresel aktivite yokluğu olarak sıralanabilir. ${ }^{[8]}$ Bunker ve Anthony, rotator intervaldeki kapsül ve korakohumeral ligament eksizyonu yapmışlar ve 12 hastada sinovyal bir tutulum görmezken, bazı düz kas fenotipine değişim (myofibroblast) eşliğinde aktif fibroblastik proliferasyon olduğunu göstermişler; bu tabloyu da Dupuytren benzeri bir hastalık olarak tanımlamışlardır. ${ }^{[9]}$ Yine bu çalışmada, immünohistokimyasal araştırmalarla, sitokontraktil bir protein olan 'vimentin'e karşı monoklonal antikorlar olduğu gösterilmiştir.

\section{SINIFLAMA}

Donuk omuz, primer ve sekonder olmak üzere iki ana başıık altında incelenebilir. ${ }^{[10]}$ Sekonder etmenler: kalsifik tendinit; rotator manşet yaralanmaları; glenohumeral ve akromioklavikuler artrit; uzamış immobilizasyon ve posttravmatik durumlar olarak sıralanabilir.

İntrensek faktörler: rotator manşet bozuklukları; biseps uzun başı tendiniti; akromioklaviküler artrit gibi faktörlerdir. Ekstrensek olanlar ise, omuzun uzağında bulunan patolojilerdir. İskemik kalp hastalıkları, pulmoner bozukluklar, servikal diskopati, Parkinson hastalığı, humerus cisim kırıkları, kardiyotorasik veya meme cerrahisi geçirilmesi bunlar arasında sayılabilir. Diabetes mellitus, hipotiroidi, hipertiroidi, hipoadrenalizm gibi hastalıklar da sistemik bozukluklar olarak sayılabilir. Etiyoloji nonoperatif tedavi açısından önemlidir. Primer donuk omuz konservatif tedaviye iyi cevap verirken, cerrahi sonrası gelişen donuk omuz konservatif tedaviye iyi cevap vermez.

\section{EVRELEME}

Günümüzde adezif kapsülit sınıflaması dört evreden oluşur; semptom, bulgular ve histopatolojik değişiklikler her evrede farklılık göstermektedir. ${ }^{[11]}$ Bu evreler, iyi tanımlanmış, farklı, ayrı evreler olmaktan çok, aynı hastalığın birbirini izleyen evreleridir.

\section{Evre I}

Başlangıç evresi olarak isimlendirilir. Hasta, aktif ve pasif hareket kısıtılığından yakınmaktadır. İstirahat halindeyken ve ani hareketler sonrası ağrı vardır. Semptomlar üç aydan az bir süredir devam etmektedir. İstirahat sırasında ve gece ağrısı vardır. İlerleyici bir hareket kaybı vardır; öne fleksiyon, abduksiyon, iç ve dış rotasyon en kısıtlı olanlardır. Anestezi altındaki muayene ve eklem içi lokal anestezik enjeksiyonunu takiben hareket kaybı tamamen düzelir veya minimal bir hareket kaybı kalır. Artroskopik muayenede yaygın hipervasküler glenohumeral sinovit izlenir. Patolojide, nadir inflamatuvar hücre infiltrasyonu, hipertrofikhipervasküler sinovit ve normal kapsül vardır.

\section{Evre II}

Donma evresi olarak isimlendirilir. Semptomlar 3-9 aydan beri mevcuttur; kronik ağrı ve hareketlerde ilerleyen kayıp vardır. Gece ve istirahat ağrıları vardır ve ciddi uyku bozukluğuna yol açar. Öne fleksiyon, abduksiyon, iç ve dış rotasyon ileri derecede kısıtlıdır. Eklem içi lokal anestezik enjeksiyonu sonrası ya da skalen blok sonrası muayene ile hareketlerde kısmi bir düzelme sağlanabilir ve ağrı düzelebilir. Artroskopide yaygın, pedinküler sinovit ve gergin kapsül vardır. İnflamatuvar infiltrasyon yoktur ve hipertrofik-hipervasküler sinovit ile perivasküler ve subsinovyal nedbe formasyonu ve kapsüler fibroplazi vardır.

\section{Evre III}

Donuk evre olarak isimlendirilir. Gece veya istirahat halinde ağrı minimaldir fakat belirgin bir hareket kısıtlılığı vardır. Semptomlar yaklaşık 9-15 aydır mevcuttur. Lokal anestezik enjeksiyonu veya anestezi altındaki muayene ile hareket açıklığı değiş̧mez. Artroskopide hipervasküler olmayan fibrotik sinoyumun artıkları izlenir. Kapsüler biopside, yoğun, hipersellüler kollajen doku ve belirgin hipertrofi veya hipervaskülaritesi olmayan ince sinovyal tabaka izlenir.

\section{Evre IV}

Çözülme evresi olarak adlandırılır. Minimal ağrı ile birlikte omuz hareketlerinde ilerleyen bir düzelme mevcuttur. Bu dönemde hastalara nadiren cerrahi uygulandığından, artroskopik veya patolojik bilgi yoktur. ${ }^{[12]}$ 


\section{TANI}

Tanı, tıbbi hikaye, klinik ve radyolojik muayene ve diğer omuz patolojilerinin ekarte edilmesi ile konur. Hastalığın ilk evresindeki şikayetler sıklıkla 'sıkışma sendromu'na benzer. Çoğu hastada travma öyküsü yoktur. Genellikle sinsi başlangıçlı bir ağrı vardır; bu ağrıyı takiben omuzda hareket kısıtlılığı başlar. Erken evrelerde gece ve istirahat ağrısı yaygındır. Tıbbi hikayede, diyabet başta olmak üzere, hipertiroidi, hipotiroidi, hipoadrenalizm, Parkinson hastalığı, kalp hastalıkları sorgulanmalıdır. Yakın zamanda geçirilen kardiyotorasik cerrahiler, radikal boyun diseksiyonları da sekonder donuk omuza yol açabilirler. HIV enfeksiyonu tedavisinde kullanılan bazı proteaz inhibitörlerinin de donuk omuza yol açtığı rapor edilmiştir. ${ }^{[13,14]}$

Klinik muayenede, hastalığın erken evrelerinde tek bulgu, omuzun aşırı hareketlerinde ağrı olmasıdır. Evre I ve II'de palpasyon ile deltoid yapışma yerine uzanan anterior ve posterior kapsülde ağrı vardır. İleri dönemde deltoid ve supraspinatusta, hareketsizliğe bağlı hafif-orta atrofi olabilir. Omuz dış rotasyonunun tamamen kaybı donuk omuz için patognomonik olabilir (Resim). Eğer pasif dış rotasyon tam, aktif dış rotasyon yok ise, muhtemel rotator manşet yırtığından şüphelenilmelidir. Donuk omuzda, skapulotorasik eklemden yapılan hareketlerin de çoğu etkilenir. En az etkilenen hareketler ekstansiyon ve horizontal adduksiyondur. Tanı için özel bir muayene testi yoktur.

Rutin radyografiler, diğer patolojileri ekarte etmek için çekilir. Genellikle normaldir, bazı olgularda osteopeni izlenebilir.

Rotator manşet yırtığı gibi diğer patolojieri saptamak için manyetik rezonans (MR) görüntüleme de kullanılır; donuk omuz tanısı koymak için rutin olarak kullanılan bir yöntem değildir. MR artrografi, kapsül kalınlığını ve azalmış eklem hacmini göstermede yararIıdır. ${ }^{[15]}$

Ultrason ve Doppler, yumuşak dokuda inflamatuvar değişiklikleri ve vasküleriteyi değerlendirmek için günümüzde popülarite kazanmaktadır. ${ }^{[16]}$
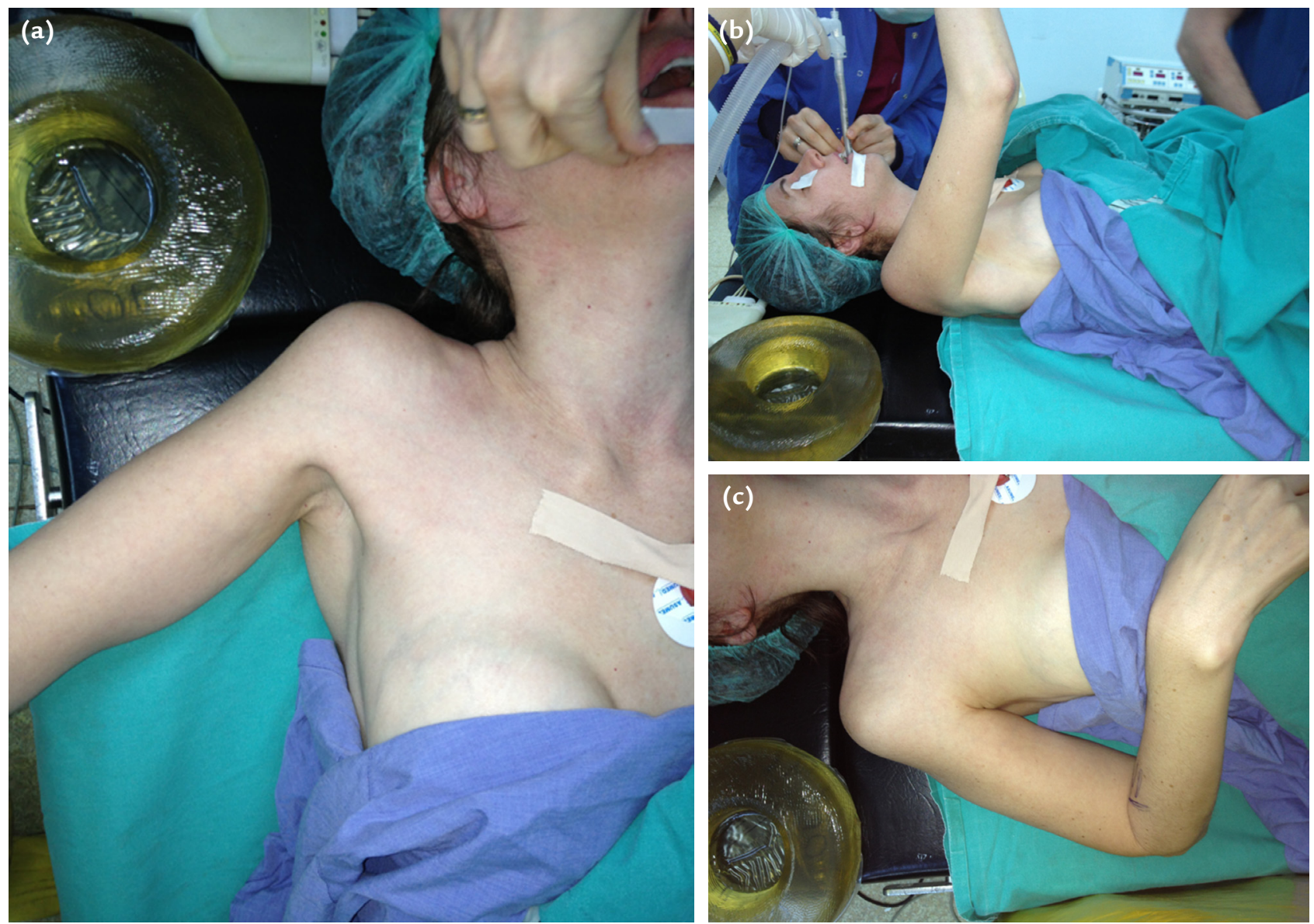

Resim. a-c. Kırk iki yaşındaki kadın hastanın sağ omuzu. Artroskopik girişim öncesi genel anestezi altında, omuz abduksiyonu $30^{\circ}$ (a). Omuz fleksiyonu $60^{\circ}$ (b). Omuzda $20^{\circ}$ internal rotasyon kontraktürü mevcut (c). 
Ayırıcı tanıda bazı omuz bölgesi bakteriyel enfeksiyonlarının, glenohumeral eklem tüberkülozunun ${ }^{[17]}$ ve bazı tümörlerin ${ }^{[18]}$ göz önünde bulundurulması yanlış tanıyı önleyecektir.

\section{TEDAVi}

Donuk omuzda tedavi planına başlamadan önce, hastalığın hangi aşamada olduğunun belirlenmesi uygulanan tedavinin başarısı yönünden önem arz etmektedir. Bu amaçla, uygulanacak tedavinin planlanmasından önce hastanın semptomlarının, tıbbi geçmişinin ve omuz eklem hareketlerinin değerlendirilmesi gerekir. Donuk omuzda, hastalarda doğal seyir tam olarak ortaya konmamış olsa da, genellikle ortalama 2-3 yıl içinde iyileşme olabileceği belirtilir. Son çalışmalarda ise artık yazarlar bu süreler konusunda daha az iyimser sonuçlar bildirmektedirler. ${ }^{[19]}$ Tedavinin amacı, hastaların en önemli şikayetlerinden biri olan ağrının kontrolü ve eklem hareket ve gücünün yeniden kazanılmasıdır. Donuk omuz tedavisinde farklı tedavi yöntemleri tanımlanmıştır. Tedavileri cerrahi dışı ve cerrahi şeklinde iki ana başlığa ayırabiliriz.

\section{Cerrahi dışı tedavi seçenekleri}

Başlangıç tedavi yöntemi konservatif tedavidir. ${ }^{[20]}$

\section{Non-steroid anti-inflamatuvar ilaçlar}

Nonsteroid anti-inflamatuvar ilaçlar, inflamasyonun ve ağrının önlenmesi amacıyla erken inflamatuvar dönemde kullanılabilir. ${ }^{[21]}$ ilaçlar genellikle fizyoterapistler tarafından uygulanan veya öğretilen egzersizler ile birlikte uygulanır. Bu tedavi yöntemi çoğunlukla donuk omuzun ilk aşamasında uygulanır. Egzersizler ağrılı olur ve öncesinde omuza uygulanan sıcak uygulama ve ağrı kesicilerin desteği ile hastaların egzersizlerini daha rahat yapmaları sağlanır.

\section{Fizik tedavi}

Fizik tedavide uygulanan bazı özel egzersizler ile eklem hareketleri yeniden kazanılabilir. Bu egzersizler bir terapist kontrolünde ve ev egzersizleri şeklinde uygulanabilir. Bilinçsizce yapılan egzersizler hastalığın seyrini arttırabilir. Uygulama öncesinde omuz eklemine sıcak uygulanması egzersizler öncesinde yardımcı olmayabilir. Egzersizler gerdirme ve eklem hareket açıklığını arttırmaya yöneliktir.

Dış rotasyon - pasif germe: Kişi, etkilenen tarafının eli ile, dirseği $90^{\circ}$ olacak şekilde bir kapının kenarına tutunur; ardından el ve dirseğini sabit tutarak vücudunu sağlam omuzuna doğru çevirerek etkilenen omuzunu dış rotasyona zorlar. Bu işlemi 30 saniye yapıp, ardından gevşer. ileri fleksiyon - supin pozisyonu: Kişi supin pozisyonda yatar. Etkilenmeyen tarafın eli ile etkilenen tarafın dirseğine destek olarak, kolunu baş üstüne doğru getirip gerdirir. Bu işlemi 15 saniye yapıp, ardından gevşer.

Karşı tarafa kol gerdirme: Kişi etkilenmeyen tarafının eli ile etkilenen taraf dirseğine destek olarak, kolunu göğsüne yaklaştırır. Bu işlemi 30 saniye uygulayıp, ardından gevşer.

\section{Steroid enjeksiyonu}

Evre 1'de ve Evre 2'nin başlangıcında inflamasyonun baskılanması amacıyla kullanılabilir. Glenohumeral ekleme steroid enjeksiyonu ile birlikte egzersiz uygulaması günümüzde en çok bilinen kombinasyonlardan biridir. ${ }^{[22]}$ Fizik tedavi ile yeterli cevap alınamadığı veya yeterli yapılmadığı düşünüldüğünde, takviye olarak enjeksiyon denenebilir. Eklem içi uygulama nedeniyle klasik steroid komplikasyonları görülmez. Radyolojik rehberlik olmadan glenohumeral ekleme steroid enjeksiyonu yerine, ulaşımın daha kolay olduğu subakromiyal ekleme enjeksiyon sonrasında da donuk omuz semptomlarının azaldı̆̆ı yönündan bazı yayınlar bulunmaktadır. ${ }^{[23,24]}$ Oh ve ark. bir çalışmada, steroid enjeksiyonu bir grupta glenohumeral ekleme ve diğer grupta ise subakromiyal ekleme yapmışlardır. Her iki gruba non-steroid anti-inflamatuvar ilaçlar ve egzersizler de verilmiştir. Sonuçta istatistiksel olarak bir fark olmamakla birlikte, subakromiyal grubunda kısa dönem takip sonuçlarının daha iyi olduğu görülmüştür. ${ }^{[22]}$

\section{Oral steroid tedavisi}

Oral steroid tedavisi, erken dönemde ağrı kontrolünde fayda sağlamaktadır. Oral prednizolon ile plasebonun karşılaştırıldığı, 42 hastanın değerlendirildiği randomize çift kör çalışmada, erken dönemde semptomlarda azalma saptanmış ancak uzun dönem takiplerinde fark görülememiştir. ${ }^{[25]}$

\section{Cerrahi tedavi}

Anti-inflamatuvar ilaçlara, eklem içi enjeksiyonlara, fizik tedavi veya manipülasyonlara rağmen hastanın şikayetlerinde azalma olmuyorsa, özellikle üçüncü aşama omuzlarda cerrahi tedavi seçeneği düşünülmelidir. ${ }^{[26]} \mathrm{Bu}$ aşamada hasta ile doktorun cerrahi seçenekleri ve cerrahi riskleri mutlaka konuşmalıdır. Cerrahi tedavilerin amacı, sert olan omuz eklemi kapsülünü gevşetmek ve germektir. Günümüzde en çok kullanılan yöntemlerin başında anestezi altında manipülasyon ve omuz artroskopisi gelir. 


\section{Anestezi altında manipülasyon}

Konservatif tedaviye rağmen altı aydır devam eden ilerleyici ağrı ve hareket kısıtlığı durumunda uygulanır. Bu işlemde hasta anestezi altında iken, omuz ekleminde patolojiye neden olan daralmış kapsül ve skar dokusuna cerrah tarafindan kuvvet uygulayarak gerdirilip, yırtılması amaçlanır. İşlem genellikle genel anestezi, subklavyen veya interskalen sinir bloğu altında hasta supin pozisyonda iken önce kol fleksiyona, sonra $90^{\circ}$ abduksiyonda iken dış rotasyona, ardından da abduksiyonda iç rotasyona getirilir. Son olarak da, karşı taraf kol adduksiyona getirilir; hareketler sırasında direncin olduğu yere kadar getirilip, kibarca zorlanır. ${ }^{[27]}$ Bilinçsizce yapılan zorlamalar humerus kırıklarına, omuz çıkıklarına, brakiyal pleksus yaralanmasına ve rotator manşet kaslarının yırtılmasına neden olabilir. İşlem sonrasında ağrı kesici desteğine başlanıp erken hareket ve egzersiz gerekir. Aksi takdirde yeniden yapışıklıklar oluşabilir. İşlem sırasında omuz hareketlerinde açılma olmuyorsa, daha fazla zorlanmamalı ve diğer cerrahi seçenekler düşünülmelidir. Uygun yapıldığı takdirde anestezi altında manipülasyonlar, diğer cerrahi seçeneklere göre daha güvenli ve uzun dönem sonuçlarının daha iyi olduğu söylenmektedir. ${ }^{[27]}$ Yüz yirmi beş hastanın değerlendirildiği randomize bir çalışmada, anestezi altında manipülasyonun ev içi egzersiz programı uygulanan hastalara göre işlem sonrası üçüncü ayda daha fazla eklem hareket açıklığı elde edildiği rapor edilmiştir. [28]

\section{Omuz artroskopisi}

Anestezi altındaki manipülasyonlarda oluşabilecek komplikasyonlardan dolayı daha güvenli olduğu için omuz artroskopisi tercih edilebilir. Skalen blok veya genel anestezi altında cerrahın alışkın olduğu pozisyonda, lateral dekubit veya şezlong pozisyonunda uygulanır. Cerrahinin başarısı iyi bir görüntüye bağlıdır. Bu amaçla artroskopik pump setinin $50-10 \mathrm{mmHg}$ arasında kullanılması tavsiye edilir. Standart cerrahiye, omuz artroskopisinde olduğu gibi posterior portalden başlanır. illk olarak biseps uzun başı görüntülemesi ile başlanır. Yeterince gevşetme yapılana kadar ekleme çok fazla kontrakte olduğu için, infra glenoid aralığı değerlendirmek zordur. Anterior portalden gönderilecek radyofrekans probu ile labrumun kenarından orta gleno humeral ligamanı kesilerek, gevşetmeye başlanır. Subskapularis genellikle skar dokusu ile kaplıdır. Tendonun parlak lifleri görünene kadar skar dokusu eksize edilmelidir. Ardından rotator aralık, supraspinatus tendonun ön kısmından gevşetilir. Supraspinatus tendonuna hasar vermemek için dikkat edilmelidir. Tüm bu dokular korakoid proçesin inferolateral kemik yüzey görüntülene kadar kesilip çıkartılır. Kapsülotomi bisepsin uzun başının yapışma yerinden posterior olarak saat dokuz hizasına kadar yapılır. İnferior kapsülün altından aksiller sinir geçmesi nedeniyle koter burada kullanılmamalıdır. ${ }^{[26]}$ Omuz artroskopisine izin vermeyecek düzeyde aşırı kontrakte eklemlerde açık gevşetme de uygulanabilir. Kapsülün ne kadar gevşetileceği konusunda tartışmalar mevcuttur. Anterior ve inferior kapsüler gevşetme nispeten sık yapılırken posterior gevşetme ilerleyici internal rotasyon kısıtlılığında yapılabilir. Aşırı gevşetmenin aksiller sinir felci, omuz dislokasyonu gibi potansiyel artsorunları bulunmaktadır. ${ }^{[2]}$

\section{Botilinum toksini uygulaması}

Chen, donuk omuzda eklem içi botulinum toksin enjeksiyonunu araştırmıştır. Botulinum toksin enjeksiyonunun steroide göre ağrı kesici etkisinin daha uzun sürdüğünü ve yan etkilerinin daha az olduğunu, etkili ve alternatif bir tedavi olabileceğini belirtmiştir. ${ }^{[29]}$

\section{Cerrahi sonrası}

Cerrahi işlemler sonucunda kazanılan eklem hareketlerinin devamlılığını sağlamak amacıyla fizik tedaviye, cerrahi sonrası hemen başlanması gerekmektedir. İyileşme dönemi altı hafta ile üç ay arası sürebilir.

Günümüzde donuk omuz ile ilgili çalışmalar yapılmış ve konu ile ilgili birçok tedavi yöntemi bulunmuştur. Tedavi planlaması öncesinde en uygun tedavinin verilebilmesi için hastanın iyi bir şekilde değerlendirilmesi önem taşımaktadır.

\section{KAYNAKLAR}

1. Bhargav D, Murrell GAC. Basic Science of Adhesive Capsulitis. Techniques in Shoulder \& Elbow Surgery 2011;12(4):126-9.

2. Lynch TS, Edwards SL. Adhesive capsulitis: current concepts in diagnosis and treatment. Current Orthopaedic Practice 2013;24(4):365-9. CrossRef

3. Neviaser JS. Adhesive capsulitis of the shoulder. A study of the pathological findings in periarthritis of the shoulder. J Bone Joint Surg Am 1945;27(2):211-22.

4. Tasto JP, Elias DW. Adhesive capsulitis. Sports Med Arthrosc 2007;15(4):216-21.

5. Tighe CB, Oakley WS Jr. The prevalence of a diabetic condition and adhesive capsulitis of the shoulder. South Med J 2008;101(6):591-5. CrossRef

6. Lho YM, Ha E, Cho CH, Song KS, Min BW, Bae KC, Lee KJ, Hwang I, Park HB. Inflammatory cytokines are overexpressed in the subacromial bursa of frozen shoulder. J Shoulder Elbow Surg 2013;22(5):666-72. CrossRef

7. Xu Y, Bonar F, Murrell GA. Enhanced expression of neuronal proteins in idiopathic frozen shoulder. J Shoulder Elbow Surg 2012;21(10):1391-7. CrossRef

8. Uhthoff HK, Boileau P. Primary frozen shoulder: global capsular stiffness versus localized contracture. Clin Orthop Relat Res 2007;456:79-84. 
9. Bunker TD, Anthony PP. The pathology of frozen shoulder. A Dupuytren-like disease. J Bone Joint Surg $\mathrm{Br}$ 1995;77(5):677-83.

10. Chambler AF, Carr AJ. The role of surgery in frozen shoulder. J Bone Joint Surg Br 2003;85(6):789-95.

11. Neviaser AS, Hannafin JA. Adhesive capsulitis: a review of current treatment. Am J Sports Med 2010;38(11):2346-56. CrossRef

12. Sheridan MA, Hannafin JA. Upper extremity: emphasis on frozen shoulder. Orthop Clin North Am 2006;37(4):531-9.

13. Grasland A, Ziza JM, Raguin G, Pouchot J, Vinceneux P. Adhesive capsulitis of shoulder and treatment with protease inhibitors in patients with human immunodeficiency virus infection: report of 8 cases. J Rheumatol 2000;27(11):2642-6.

14. De Ponti A, Viganò MG, Taverna E, Sansone V. Adhesive capsulitis of the shoulder in human immunodeficiency viruspositive patients during highly active antiretroviral therapy. J Shoulder Elbow Surg 2006;15(2):188-90.

15. Song KD, Kwon JW, Yoon YC, Choi SH. Indirect MR arthrographic findings of adhesive capsulitis. AJR Am J Roentgenol 2011;197(6):W1105-9. CrossRef

16. Walmsley S, Osmotherly PG, Walker CJ, Rivett DA. Power Doppler Ultrasonography in the Early Diagnosis of Primary/ Idiopathic Adhesive Capsulitis: An Exploratory Study. J Manipulative Physiol Ther 2013:S0161-4754(13)00109-7. CrossRef

17. Li JQ, Tang KL, Xu HT, Li QY, Zhang SX. Glenohumeral joint tuberculosis that mimics frozen shoulder: a retrospective analysis. J Shoulder Elbow Surg 2012;21(9):1207-12. CrossRef

18. Robinson D, Halperin N, Agar G, Alk D, Rami K. Shoulder girdle neoplasms mimicking frozen shoulder syndrome. J Shoulder Elbow Surg 2003;12(5):451-5.

19. Akpinar S, Ozalay M, Hersekli MA, Ozkoç G, Tandoğan RN. Arthroscopic capsular release for frozen shoulder. Acta Orthop Traumatol Turc 2003;37(3):213-8.
20. Levine WN, Kashyap CP, Bak SF, Ahmad CS, Blaine TA, Bigliani LU. Nonoperative management of idiopathic adhesive capsulitis. J Shoulder Elbow Surg 2007;16(5):569-73.

21. Hsu JE, Anakwenze OA, Warrender WJ, Abboud JA. Current review of adhesive capsulitis. J Shoulder Elbow Surg 2011;20(3):502-14. CrossRef

22. Oh JH, Oh CH, Choi JA, Kim SH, Kim JH, Yoon JP. Comparison of glenohumeral and subacromial steroid injection in primary frozen shoulder: a prospective, randomized short-term comparison study. J Shoulder Elbow Surg 2011;20(7):103440. CrossRef

23. Sethi PM, Kingston S, Elattrache N. Accuracy of anterior intraarticular injection of the glenohumeral joint. Arthroscopy 2005;21(1):77-80.

24. Carette S, Moffet H, Tardif J, et al. Intraarticular corticosteroids, supervised physiotherapy, or a combination of the two in the treatment of adhesive capsulitis of the shoulder: a placebo-controlled trial. Arthritis Rheum 2003;48(3):829-38.

25. Buchbinder R, Hoving JL, Green S, Hall S, Forbes A, Nash P. Short course prednisolone for adhesive capsulitis (frozen shoulder or stiff painful shoulder): a randomised, double blind, placebo controlled trial. Ann Rheum Dis 2004;63(11):1460-9.

26. Berghs BM, Sole-Molins X, Bunker TD. Arthroscopic release of adhesive capsulitis. J Shoulder Elbow Surg 2004;13(2):180-5.

27. Farrell CM, Sperling JW, Cofield RH. Manipulation for frozen shoulder: long-term results. J Shoulder Elbow Surg 2005;14(5):480-4.

28. Kivimäki J, Pohjolainen $T$, Malmivaara A, Kannisto $M$, Guillaume J, Seitsalo S, Nissinen M. Manipulation under anesthesia with home exercises versus home exercises alone in the treatment of frozen shoulder: a randomized, controlled trial with 125 patients. J Shoulder Elbow Surg 2007;16(6):722-6.

29. Chen HS, Chang KH, Kang JH, Hsu YH, Hsu AC, Chen SC. Treatment of frozen shoulder with intra-articular injection of botulinum toxin in shoulder joints. Med Hypotheses 2011;77(2):305-7. CrossRef 